\title{
Determining the revenue contribution of logistics customer service improvements: a multi criteria decision making approach
}

Philip Wessely ${ }^{1}$ and Erik Hofmann ${ }^{2^{*}}$

* Correspondence: erik.hofmann@unisg.ch

${ }^{2}$ Logistics Management, University of St.Gallen, St.Gallen, Switzerland Full list of author information is available at the end of the article

\begin{abstract}
In operations and service management generating revenues is as important as reducing costs. Although logistics customer service is an important measure for executives, little research has been conducted to quantify the extent to which improvements of service levels contribute to a company's revenues. The paper applies existing fuzzy-based methods to monetarily determine the revenue contribution of logistics customer service. A logistics customer service-revenue curve and its influencing parameters are derived to obtain a quantitative relation. The method of the analytical hierarchy process is evolved dynamically by involving competitors and customer reactions. A case study from the consumer goods industry illustrates the main findings.
\end{abstract}

Keywords: Operations management; Fuzzy sets; Analytical hierarchy process; Supply chain initiative; Customer satisfaction; Value creation

\section{Background}

Since its detection in the early 1990s, supply chain management (SCM) has been widely accepted and discussed (Ellram and Liu 2002). Although quality measures, such as the logistics service level, refer to a company's performance, examinations of SCM often focus on cost reductions (Ballou 2006). In order to obtain a holistic value-based examination, the impact of SCM on a company's costs and revenues has to be considered likewise. In the recent past, researchers increasingly focused on the financial performance of SCM including costs, revenues and working capital (e.g. Hofmann and Locker 2009; Lambert and Burduroglu 2000; Pohlen and Coleman 2005). They state that there is a link between SCM, logistics customer service (LCS) and revenues. While these interrelations were mainly captured on a conceptual basis, there still remains a need to monetarily operationalize the extent to which LCS offerings actually contribute to company's revenues. In practice, this shortcoming has led decision makers to regard LCS as an objective which has to be achieved at minimum cost (Ballou 2006). Consequently, unused potential of SCM for revenue enhancing exists. Beside this effect within operational business, a determination of the revenue contribution in advance might support executives in decision-making whether to invest into SCM or not. The prediction of changes in revenues proves to be arduous since it mainly depends on corporate external factors, such as customers' behavior or competition (Wouters 2006). The information that is available about this kind of 
behavior is often solely of non-financial nature, like practical knowledge and experts' estimations. Accordingly, a determination of the revenue contribution of service improvements can be used to assess inter-organizational collaboration's benefit and therefore to promote the implementation of SCM within companies.

Based on this background, the present paper's objective is to provide an approach to determine the extent to which altering LCS levels contribute to company's revenues. Although in terms of LCS, costs have to be considered besides revenues in order to maximize associated profits, the focus of the present paper is on revenues (Ballou 2003). This shall not indicate a shift in focus from profit maximization to revenue maximization but underlines the need for calculating the revenue contribution of LCS improvements. A determination of associated costs has to be opposed to the results generated by the introduced approach.

Starting point of the following considerations is a certain supply chain initiative (SCI) (Figure 1). It is assumed that the implementation of such an initiative affects - beside others - the LCS positively. The service level improvement again has an impact on the company's financial performance (especially revenues, costs, current assets and fixed assets). As the relationship between SCI, service improvements and costs as well as assets is well examined (Wouters 2006), the paper at hand particularly stresses the monetarily connection between LCS levels and revenues. Obviously, the SCI itself is of inferior interest and is seen as an independent variable.

In order to obtain the outlined objectives, the paper is structured as follows: The first two sections give a concise overview of the methodology applied and the relevant background. Then, the conceptual configuration of the fuzzy-based approach is introduced and the results from the developed model are presented in a numerical example from the Swiss consumer goods industry. Finally, a discussion based on previous experience is offered. The paper closes with a brief conclusion.

\section{Methods}

\section{Overall approach}

The authors have chosen a conceptual research approach based on constructivism due to its ability to generate new knowledge (Kasanen et al. 1993). Several methods were applied.

First, the paper starts off by studying the (logistics) customer service and customer satisfaction literature that is mainly rooted in the research fields of operations, SCM and marketing. A quantitative forecast of revenue response to altering LCS is difficult,

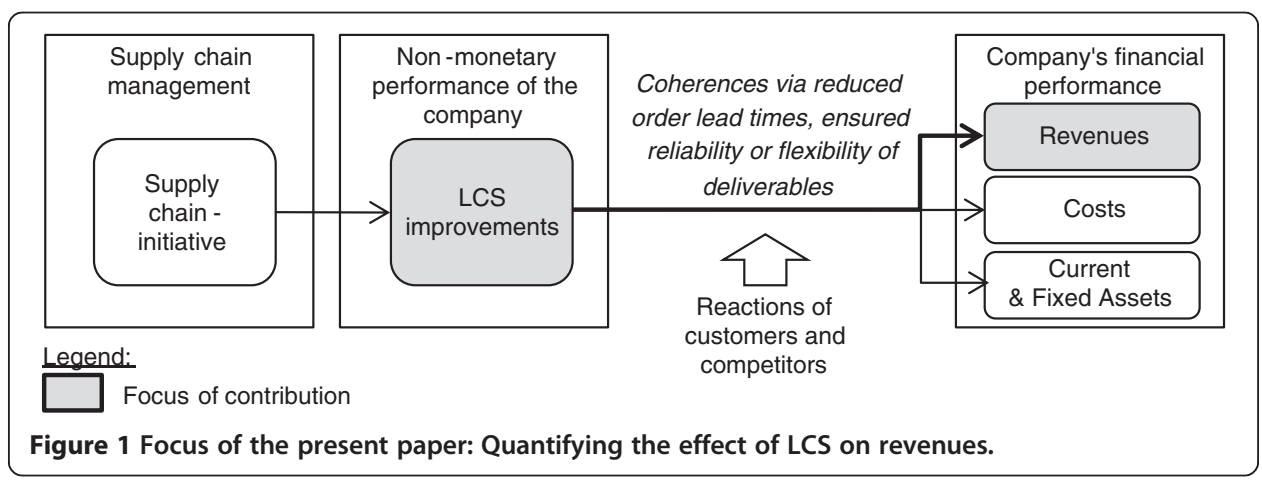


due to external determinants like customers' and competitors' reactions. Instead of an algebraic and therefore quantitatively tangible description of relevant relations, there is a qualitative one available in terms of know-how in a company's departments, for example sales and distribution.

Second, to meet the non-financial nature of LCS and the vague character of linguistic evaluations the authors choose a fuzzy-based approach. Fuzzy applications were used in operations, SCM and marketing research, as for example, in determination of critical service attributes (Deng 2008) or analyzing of inventory policies (Handfield et al. 2009).

Third, to validate and optimize the different settings of the fuzzy parameters, such as the definition of membership functions and rules of inference, the quantification model was tested in in-depth exploratory interviews for route decision makers to enable a stepwise improvement (Meredith 1993). Although the model employs existing techniques such as fuzzy logic and the analytical hierarchy process (AHP) an innovative adaption is undertaken by integrating dynamic aspects in terms of a pre-post comparison. For that reason, the behavior of customers and competitors is equally considered. The data base for the optimization and adjustment of the parameters is provided by sales and logistics executives from eleven cooperating international companies within the consumer goods and pharmaceutical industry.

From a technological perspective, the improvement and adjustment of the model was made by using the fuzzy logic toolbox version 2.2.10 of MathWorks' MATLAB. Finally, a case study from the Swiss consumer goods industry illustrates the main results of the model.

\section{Literature review}

LCS in the supply chain affects two entities - the vendor of a product and the consumer who is the recipient of the product. Numerous researches have dealt with this relation describing (a) the multi-dimensional construct of LCS as well as outlining (b) the cause-and-effect between LCS, customer satisfaction and firm performance. A review of the two literature streams shall give a brief overview of the current state of research.

ad (a) LCS is a multi-dimensional construct with different elements which can be examined by several computational approaches (Parasuraman et al. 1988). The comprehension of LCS comprises comparatively simple definitions, like lead time, and a broad understanding consisting of an extensive variety of variables (e.g. Mentzer et al. 1999; Parasuraman et al. 1985). A study by Sterling and Lambert (1989) shows that the most important single variable of LCS appears to be lead time. Techniques for measuring service level are manifold and comprise, for example, audits (Takeuchi and Quelch 1983), gap analysis (Zeithaml et al. 1988), multiple-item scales (Parasuraman et al. 1988; Cronin and Taylor 1994) or the analytic hierarchy process (Chow and Luk 2005). Except for the latter all these methods focus on internal service quality and disregard competition which drives customer expectations in service quality over time. Besides LCS the influence of product, price and promotion have to be taken into account (Lambert and Stock 1993). An extraction of one single determinant's effect seems to be difficult and may be one reason why executives preferably tend to focus on reducing costs instead of generating revenues in the context of an SCI (Ballou 2006).

ad (b) In the literature it is stated that a high level of LCS provides a basis for customer satisfaction, which in turn affects the financial performance of a company (Dresner and 
$\mathrm{Xu}$ 1995; Yeung 2008). Several authors look into this interdependency and focus on diverse perspectives of the financial impact of an increasing service level in general. For instance, Anderson et al. (1994), Luo and Homburg (2008), as well as Kamakura et al. (2002), Tracey (1998) or Vickery et al. (2003) address the effect of customer satisfaction on stock price, market share and shareholder value. Customer satisfaction has, though, an effect on important value drivers and creates shareholder value by increasing future cash flows and reducing their variability. Further research points out that satisfied customers tend to be more loyal and increase their level of purchasing over time to enhance company's revenues, which is after all led back to an outstanding service level compared to competition (Fornell et al. 2006). Although there is a lot of research looking into the causality between SCM, LCS and a company's performance by statistical or empirical analysis, only a few articles address a formal-analytical quantification of this relation (Bookbinder and Lynch 1997; Ozment and Chard 1986; Yeung 2008). Ballou (2006) introduces methods of estimating revenues associated with various levels of LCS. He distinguishes between the form of measurement (directly through LCS vs. indirectly through cost imputation) as well as the considered market (new vs. existing). Within this framework he discusses common estimation methods like experiments, price sensitivity analyses or surveys. However, computational approach to determine the revenue contribution on alterations of LCS in advance is still lacking.

To sum up, the brief literature review on LCS shows that two crucial issues exist: Firstly, besides price, product and promotion, LCS is one decisive determinant affecting customer satisfaction. Furthermore, LCS is a multi-dimensional construct existing of several variables, such as lead time and quality of delivery. All these variables are of different importance to various customer segments, depending mainly on the product and the competitive environment. Secondly, SCM provides a basis for customer satisfaction through LCS, which affects the revenues of a company. But a prediction of the degree to which an increase of LCS affects customer satisfaction and leads to higher revenues is a nontrivial problem. The answer to this problem lies in the search for methods processing qualitative and non-financial information. Hence, a fuzzy-based approach addressing this problem is introduced.

\section{Derivation of the LCS-revenue curve}

Starting point for a quantification of the effects of LCS on company's revenues is the nature of the correlation between these two variables. Such a link can be derived by known relations between LCS levels and customer satisfaction (1), customer satisfaction and customer loyalty (2), as well as customer loyalty and revenues (3). The derivation of the qualitative curve progression is shown in Figure 2.

ad (1) An increase of LCS is generally assumed to lead to higher customer satisfaction (Hsin-Hui et al. 2009). Since an intensification of LCS does not reflect in higher customer satisfaction in the same proportion, there is no linear correlation. Rather an S-shaped curve is assumed. If the offered LCS level is comparably low, an increase would lead to disproportionate high growth of customer satisfaction, while in the case of an increase of an already high service level it is vice versa (Hsin-Hui et al. 2009).

ad (2) An enhancement of customer satisfaction leads to an increase of repurchase intention (Boulding et al. 1993; Zeithaml et al. 1996), as well as repurchase behavior 


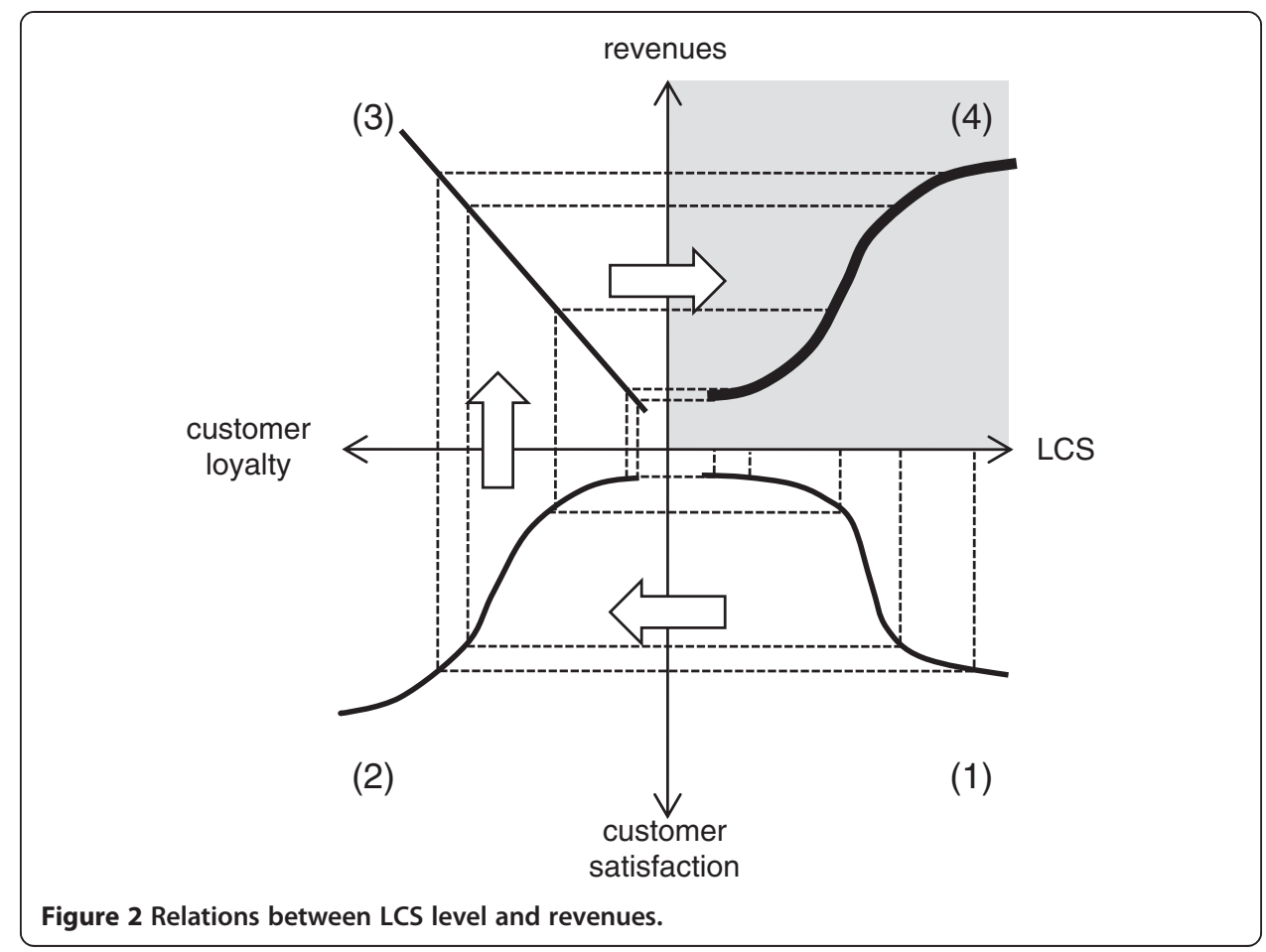

(Bolton 1998; Mittal and Kamakura 2001). The link between customer satisfaction and loyalty is likewise of non-linear nature, which is supported by data from the Swedish and American Customer Satisfaction Index (Fornell 1992; Anderson et al. 1994). This consideration is mainly based on the experience that repurchase intention is affected more strongly by dissatisfaction than by satisfaction. Therefore, research often suggests a saddle-curved shape to picture the link between customer satisfaction and loyalty (Homburg and Giering 2001).

ad (3) Higher customer loyalty leads to an increase of a customer's willingness to pay, frequency of purchase and cross-buying intention (Danaher and Rust 1996; Zeithaml et al. 1996). Furthermore, new customers are gained by word-to-mouth communication. The more satisfied a customer is with a company's LCS, the more he tends to recommend it (Boulding et al. 1993; Parasuraman et al. 1991). Although the intensity of these effects (slope of the straight line) varies with determinants, such as considered products or industry, the link between customer loyalty and revenues is of linear quality (Anderson et al. 1994; Zeithaml et al. 1996).

ad (4) By putting the information of quadrants (1) to (3) together a curve can be derived that describes the relation between a company's LCS and its revenue contribution. It comprises the explained processes of how an improvement of LCS, such as a more reliable delivery, satisfies a customer, how these more satisfied customers tend to order higher quantities from the company and participate in a wordto-mouth recommendation, that finally leads to higher revenues for the company. The quality of this correlation is S-curve shaped. (Ballou 2003) and Buxton (1975) already assumed that kind of shape for the related relation. Its main characteristic is a saturation effect which implies an increasing slope till the inflection point and a decreasing one after it. 
Since the derived shape of the LCS-revenue curve is of qualitative nature, a quantification of that relation is missing. Thereby, the exact curve progression is determined by surrounding conditions like product, customer or industry and company characteristics (Hsin-Hui et al. 2009). The subsequently introduced fuzzy-based approach ascertains the curve progression considering these factors.

\section{A fuzzy approach for quantifying the LCS-revenue curve}

The derived relationship between LCS and revenues is the basis for a quantification approach using the fuzzy set theory. As mentioned previously, the SCI which causes an alteration of LCS is not of special interest at this point. After a quantitative determination of the S-curve, the revenue contribution of any level of LCS for a given company can be read off. Four kinds of information are calculated to determine the position and shape of the S-curve (Figure 3):

I. The company's level of LCS $\left(s^{C O}\right)$ : It represents the initial point before an SCI is implemented.

II. The average industry level of LCS $\left(s^{I N D}\right)$ : It represents the inflection point of the S-curve and reflects timely adjustments of the common LCS level in a specific industry.

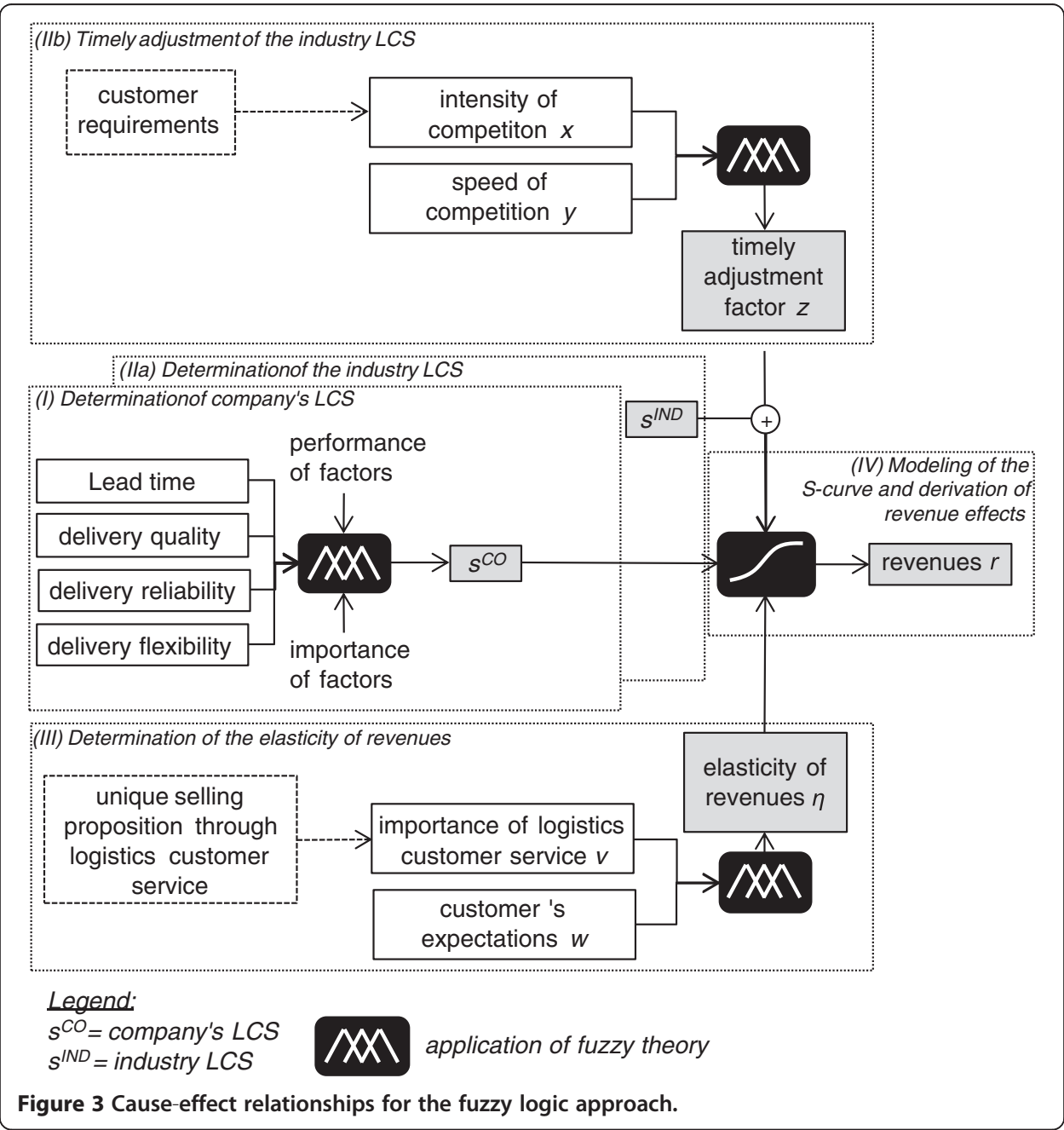


III. The elasticity of revenues against the LCS level $(\eta)$ : It reflects the slope of the S-curve.

IV. Modeling of the S-curve: The determined information is put together to display the S-curve quantitatively.

\section{(I) Determination of company's LCS $\left(s^{\mathrm{CO}}\right)$}

In the first part of the model, $s{ }^{C O}$ is calculated. This step is necessary to ensure comparability, due to a different comprehension of LCS along in theory and practice. Generally, logistics LCS is operationalized into four service factors: lead time, delivery reliability, quality and flexibility (Lambert and Stock 1993). The actual level of $s^{C O}$ is determined by conjoining their performance and importance. The subsequent approach is applied to the fuzzy performance measurement method for supply chains, introduced by Chan et al. (2003) and improved by Theeranuphattana and Tang (2008).

The specific importance weights of the service factors are determined by a fuzzy AHP (Analytical Hierarchy Process) introduced by Kwong and Bai (2002). The AHPmethod developed by Saaty (2003) is based on the idea that the priority of factors is provided by the eigenvector which corresponds to the largest eigenvalue of the pairwise comparison matrix. Consequently, if one alternative is preferred to another its eigenvalue component is larger than the one of the compared option. The use of fuzzy set theory, though, allows the integration of an expert's confidence on his subjective judgment (Kwong and Bai 2002). According to Kwong and Bai (2002) the computational procedure of the fuzzy AHP is divided into four steps.

Step 1. The importance of the service factors is evaluated. Triangular fuzzy numbers

(TFN) are used to indicate the relative strength of importance. The five TFNs $(\tilde{1}, \tilde{3}, \tilde{5}, \tilde{7}, \tilde{9})$ with the corresponding membership functions are depicted in Table 1.

Step 2 . The fuzzy comparison matrix $\tilde{A}\left(\tilde{a}_{i j}\right)$ is built by using the TFNs in a pairwise comparison. The matrix is illustrated in Eq. (1).

$$
\tilde{A}=\left[\begin{array}{cccc}
1 & \tilde{a}_{12} & \tilde{a}_{13} & \tilde{a}_{14} \\
\tilde{a}_{21} & 1 & \tilde{a}_{23} & \tilde{a}_{24} \\
\tilde{a}_{31} & \tilde{a}_{32} & 1 & \tilde{a}_{34} \\
\tilde{a}_{41} & \tilde{a}_{42} & \tilde{a}_{43} & 1
\end{array}\right]
$$

where $\tilde{a}_{i j}=\left\{\begin{array}{l}1 \text { for } \mathrm{i}=\mathrm{j} \\ \tilde{1}, \tilde{3}, \tilde{5}, \tilde{7}, \tilde{9} \text { or } \underline{1}^{-1}, \tilde{3}^{-1}, \tilde{5}^{-1}, \tilde{7}^{-1}, \tilde{9}^{-1} \text { for } \mathrm{i} \neq \mathrm{j}\end{array}\right.$

Step 3. The fuzzy eigenvalues are solved. A fuzzy eigenvalue $\tilde{\lambda}$ is a fuzzy number solution to Eq. (2).

$\tilde{A} \cdot \tilde{e}=\tilde{\lambda} \cdot \tilde{e}$

Table 1 Definition of fuzzy numbers and corresponding membership functions for the fuzzy AHP

\begin{tabular}{ccll}
\hline Intensity of importance & Fuzzy number & Definition & Membership function \\
\hline 1 & $\tilde{1}$ & Equally important & $(1,1,3)$ \\
3 & $\tilde{3}$ & Moderately more important & $(1,3,5)$ \\
5 & $\tilde{5}$ & Strongly more important & $(3,5,7)$ \\
7 & $\tilde{7}$ & Very strongly more important & $(5,7,9)$ \\
9 & $\tilde{9}$ & Extremely more important & $(7,9,9)$ \\
\hline
\end{tabular}


where $\tilde{A}$ is a $4 \times 4$ fuzzy matrix with numbers $\tilde{a}_{i j}$, and $\tilde{e}$ is a non-zero $1 \times 4$ fuzzy vector with numbers $\tilde{e}_{i}$. Under consideration of internal arithmetic and the $\alpha$-cut, Eq. (2) is equivalent to Eq. (3).

$$
\left[a_{i 1 l}^{\alpha} \cdot e_{1 l}^{\alpha}, a_{i 1 u}^{\alpha} \cdot e_{i 1 u}^{\alpha}\right] \oplus \ldots \oplus\left[a_{i 4 l}^{\alpha} \cdot e_{4 l}^{\alpha}, a_{i 4 u}^{\alpha} \cdot e_{4 u}^{\alpha}\right]=\left[\lambda \cdot e_{i l}^{\alpha}, \lambda \cdot e_{i u}^{\alpha}\right]
$$

where $\tilde{A}=\left[\tilde{a}_{i j}\right], \tilde{e}^{T}=\left[\tilde{e}_{1}, \ldots, \tilde{e}_{4}, \tilde{a}_{i j}=\left[\tilde{a}_{i j l}^{\alpha}, a_{i j u}^{\alpha}\right], \tilde{e}_{i j}^{\alpha}=\left[e_{i l}^{\alpha}, e_{i u}^{\alpha}\right], \tilde{\lambda}^{\alpha}=\left[\lambda_{l}^{\alpha}, \lambda_{u}^{\alpha}\right]\right.$

for $0<\alpha \leq 1$ and $i, j=1, \ldots, 4$.

The $\alpha$-cut is used to include the expert's confidence over his judgment. The higher the value of $\alpha$, the higher his confidence. The satisfaction for the fuzzy comparison matrix $\tilde{A}$ is incorporated by the factor $\mu$, with $0 \leq \mu \leq 1$. The larger the value of $\mu$ the higher is the degree of optimism Lee (1995). Under consideration of $\mu$, the following matrix is obtained as shown in Eq. (4).

$$
\tilde{A}=\left[\begin{array}{cccc}
1 & \hat{a}_{12} & \hat{a}_{13} & \hat{a}_{14} \\
\hat{a}_{21} & 1 & \hat{a}_{23} & \hat{a}_{24} \\
\hat{a}_{31} & \hat{a}_{32} & 1 & \hat{a}_{34} \\
\hat{a}_{41} & \hat{a}_{42} & \hat{a}_{43} & 1
\end{array}\right]
$$

where $\hat{a}_{i j}^{\alpha}=\mu a_{i j u}^{\alpha}+(1-\mu) \cdot a_{i j l}^{\alpha}$.

The values of $\alpha$ and $\mu$ have to be fixed in order to calculate the eigenvector and to identify the maximal eigenvalue.

Step 4. In the final step the relative importance of the different factors of LCS is determined through normalization of the eigenvector.

The relative importance level of each factor is used to weight its specific performance score. The performance scores are likewise derived by a fuzzy performance measurement method (Chan et al. 2003). Accordingly, the performance data of each factor is converted into performance scores by using a proportional scoring technique. Each factor is scored on a measurement scale defined individually. Its performance score ranges from 0 to 10 , where 0 is the best and 10 the worst. Hereupon, the factor performance scores are transferred to a fuzzy performance grade set which is defined by TFNs, as shown in Figure 4. Finally, the weighted average method is used for the aggregation and defuzzification of the measurement results and derivation of a crisp value of $s^{C O}$. The weighting coefficients represent the relative importance levels. A detailed discussion on the measurement and aggregation algorithm can be found at Chan and Qi (2003) and Chan et al. (2003).

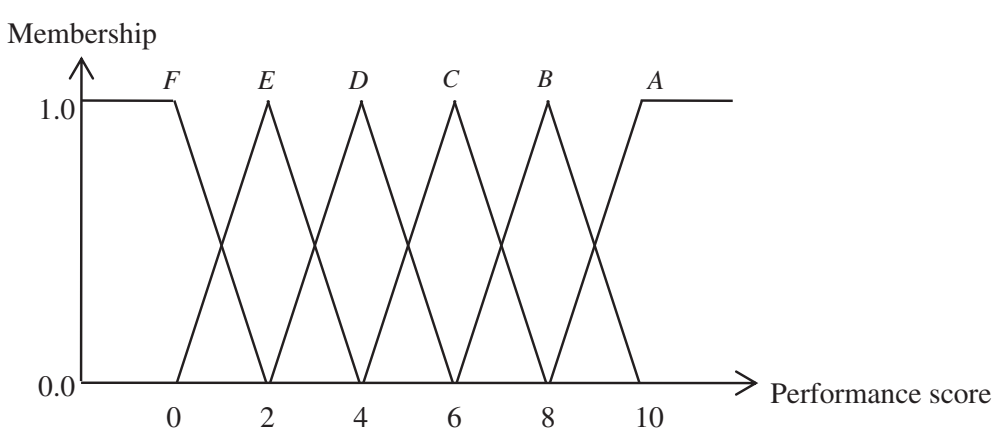

Figure 4 Triangular fuzzy grade set for the calculation of LCS. 


\section{(II) Determination of the industry's LCS $\left(s^{I N D}\right)$}

The actual level of $s^{I N D}$ has to be calculated for two reasons. Firstly, there is a different comprehension of LCS along in theory and practice (Parasuraman et al. 1988). In order to ensure comparability between $s^{C O}$ and $s^{I N D}$, both have to be calculated in the same way. Secondly, $s^{I N D}$ represents the inflection point of the sigmoid function. This assumption is based on the idea that a LCS-divergence from the industry level in a positive or negative way has the strongest effect on the company's revenues. The determination of $s^{I N D}$ is carried out analogously to the method displayed for $s^{C O}$ (IIa). However, due to competition dynamics timely adjustments have to be taken into account (IIb). This dynamic is driven by customers updating their expectations and supported by technological advance. Ceteris paribus it causes a relative decrease of the revenue effect of LCS improvements over time which has to be considered accordingly.

The timely dynamics of $s^{I N D}$ depend on the intensity and speed of competition (Boulding et al. 1993). The intensity $x$ and speed of competition $y$ are described by the fuzzy sets $\tilde{I}=\left\{\left(x, \mu_{\tilde{I}}(x)\right) \mid x \in \mathrm{U}_{x}\right\}$ and $\tilde{S}=\left\{\left(y, \mu_{\tilde{S}}(y)\right) \mid y \in \mathrm{U}_{y}\right\}$. Under consideration of specific control rules, the combination of the two input variables generates the timely dynamics factor which is denoted as $\tilde{Q}=\left\{\left(z, \mu_{\tilde{Q}}(z)\right) \mid z \in U_{z}\right\}$. The universal sets $U_{x}, U_{y}$ and $U_{z}$ as well as their fuzzy numbers are depicted in Figure 5, the corresponding control rules in Table 2. The definitions of the universal sets are the result of sensitivity analyses and stepwise optimization with sales and logistics executives from cooperating companies. The fuzzy set of the timely dynamics factor has a universe between 0 and 0.1 which has to be interpreted as the percentage change of $s^{I N D}$ within a period, naturally a year. The scale is derived from benchmarking studies by Arvis et al. (2007) and the IBM Institute for Business Value (2008).

The rule of inference is defined as a conjunction-based principle expressed by min-operation. Hence, the rule of inference can be presented in Eq. (5).

$$
x_{i} \wedge y_{j} \wedge z_{i j}=\min \left(\mu_{\tilde{I}}\left(x_{i}\right), \mu_{\tilde{s}}\left(y_{j}\right), \mu_{\tilde{\mathrm{Q}}}\left(z_{i j}\right)\right), i, j=1, \ldots, 5
$$

The mean of maximum method (MMM) is used for defuzzification to generate a crisp value for the percentage change in industry LCS (Klir and Yuan 1995). This method is adopted due to its distinct geometrical meaning making it natural from common sense. In the medium term the shape of the S-curve is supposed to be constant as its progression
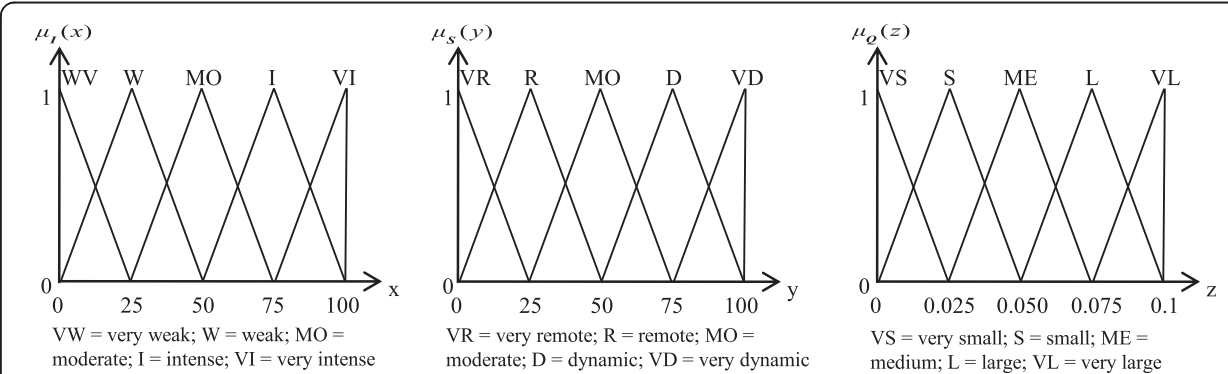

Figure 5 Input variables intensity and speed of competition as well as the output variable timely dynamics. 
Table 2 Rule base for the computation of the timely dynamics factor

\begin{tabular}{ccccccc}
\hline & \multicolumn{5}{c}{ Intensity of competition $\boldsymbol{x}$} \\
\cline { 2 - 6 } Speed of competition $y$ & VR & VS & W & MO & I & VI \\
& R & VS & S & VS & S & S \\
& MO & VS & S & ME & ME & ME \\
D & S & ME & ME & $L$ & VL \\
& VD & S & ME & $L$ & VL & $V L$ \\
\hline
\end{tabular}

represents customer's behavior which is not assumed to change rapidly. Due to that assumption, the timely adjustment is provided by scaling the abscissa. This is possible because $s^{I N D}$ stays in the inflection point of the S-curve.

(III) Determination of the elasticity of revenues ( $\eta$ )

According to Figure 2, the relationship between LCS and revenues is described by an S-shaped curve (Ballou 2003). It is described mathematically by the sigmoid function $f(p)$ shown in Eq. (6). Within this function, $e$ denotes Euler's number, $s$ refers to the LCS which is weighted to place the S-curve in the first quadrant of the coordination system, and $\eta$ defines the extent to which alterations of $s^{C O}$ contribute to company's revenues. It is referred to as the elasticity of revenues. In dependence of $\eta$ the slope of the S-curve gets steeper or straighter.

$$
f(p)=\frac{1}{1+e^{-s \cdot \eta}}
$$

In general, customer's behavior depends on a product's price and quality, the actual level of LCS and other activities like promotion (Innis and La Londe 1994). Thus, the importance of LCS against other determinants is of interest for the calculation of $\eta$ (Ballou 2003). The relative importance is calculated with a fuzzy AHP presented in Eq. (1) to (4). Moreover, the expectations of customers determine the revenue response on an alteration in LCS (Anderson et al. 1994). The expectations are based on the experience that enables customers to assess a service level they can generally expect.

Along with customer expectations, the relative importance of LCS build input variables to compute $\eta$. They are specified by the fuzzy sets $E X=\left\{\left(v, \mu_{E X}(v)\right) \mid v \in \mathrm{U}_{v}\right\}$ and $I M=\left\{\left(w, \mu_{I M}(w)\right) \mid w \in \mathrm{U}_{w}\right\}$. The elasticity of revenues $\eta$ is defined as fuzzy set $E=$ $\left\{\left(\eta, \mu_{E}(\eta)\right) \mid \eta \in \mathrm{U}_{\eta}\right\}$. The corresponding universal sets $U_{v}, U_{w}$ and $U_{\eta}$ as well as their fuzzy numbers are shown in Figure 6.

According to sensitivity analyses and stepwise optimization with sales and logistics executives cooperating companies, the fuzzy set of the elasticity of revenues is scaled from 1.0 to 1.4, as these upper and lower bound are reasonable from a mathematical point of view. The control rules for the aggregation are depicted in Table 3. The rule of inference is build by the min-operator, the defuzzification by the MMM.

(IV) Modeling of the S-curve and derivation of revenue effects

Figure 7 gives an overview of the different parameters and the shape of the S-curve in period $t=1$. The progression of the $\mathrm{S}$-curve is determined by the value of $\eta$. The 


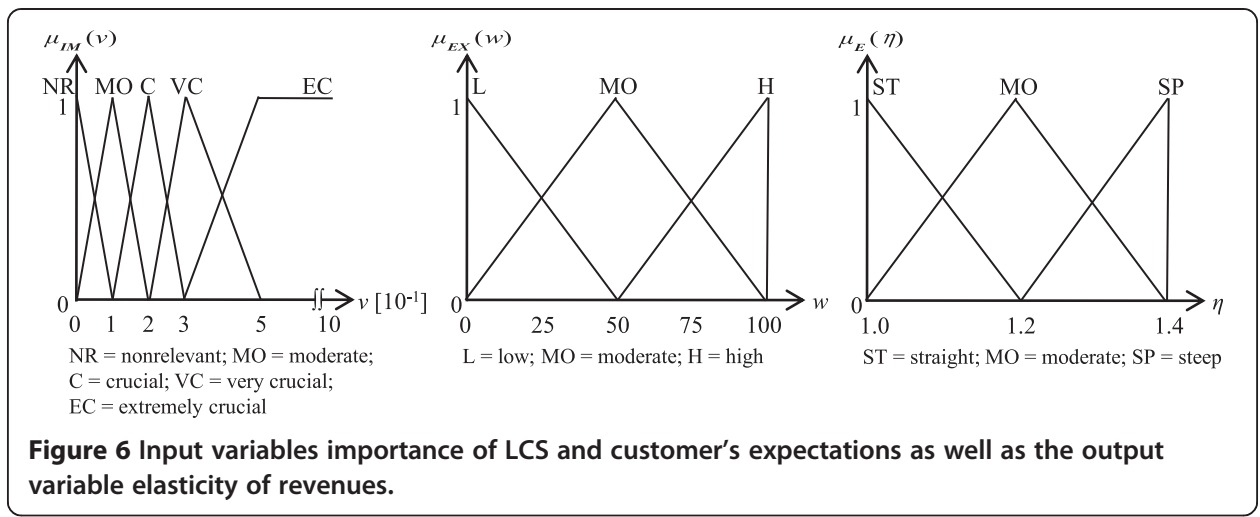

calculated industry LCS $\left(S_{1}^{I N D}\right)$ represents the inflection point of the S-curve and scales the abscissa. Conforming to the assumption that the addressed alteration of LCS takes place mainly around the industry level, the scale of the abscissa does not range from 0 to $100 \%$. The ordinate is scaled by the generated revenues $\left(r_{0}\right)$ at the actual company's level of LCS $\left(s_{0}^{C O}\right)$ in period $t=0$ and the revenues at a significant lower level as the industry's one $\left(r_{\text {min }}\right)$. The value of $r_{\min }$ needs to be estimated by a company's sales or logistics executives. The implementation of an SCI increases the company's LCS to a higher level $\left(S_{1}^{C O}\right)$. The generated revenues $\left(r_{1}\right)$ can be derived from the quantified S-curve and the scaled ordinate. At this point, the extent to which the SCI increases $S_{0}^{C O}$ is an independent variable and determined by estimation as well. Alternatively, it is definable by the means of fuzzy set theory.

In respect of an altering industry LCS, the timely dynamics result in an adjustment shown in Figure 8. An increasing industry level of LCS $\left(S_{0}^{C O}\right)$ leads to a decrease in the revenue effect of the formerly increased company's LCS. The extent of the timely dynamic of the industry level is represented by the factor $z$. Consequently, the shape of the S-curve stays the same assuming costumer's behavior to be constant in the medium term. The industry LCS shifts to the right. The remaining of the company's LCS on the same level $\left(S_{1}^{C O}=S_{2}^{C O}\right)$ results in a decrease of the revenue enhancement $\left(r_{2}\right)$. In the case of a decline in $s_{2}^{I N D}$, the effects are vice versa.

The temporal differentiation of created revenue alterations enables a net present value $(N P V)$ consideration as shown in Eq. (7).

$$
N P V_{S C-I}=\left(r_{0}-r_{1}\right)+\left(\frac{\left(r_{0}-r_{2}\right)}{(1+i)^{1}}+\ldots+\frac{\left(r_{0}-r_{2}\right)}{(1+i)^{4}}\right)
$$

The net present value, which is generated by the implementation of an SCI increasing the level of LCS $\left(N P V_{S C-I}\right)$, consists of two terms. The first term covers the revenue

Table 3 Rule base for the computation of the elasticity of revenues

\begin{tabular}{lllllll}
\hline & & \multicolumn{5}{c}{ Importance of LCS $\boldsymbol{v}$} \\
\cline { 3 - 7 } & & NR & MO & C & VC & EC \\
\hline Customer's expectations $w$ & L & ST & ST & MO & MO & SP \\
& MO & ST & MO & SP & SP & SP \\
& H & ST & MO & SP & SP & SP \\
\hline
\end{tabular}




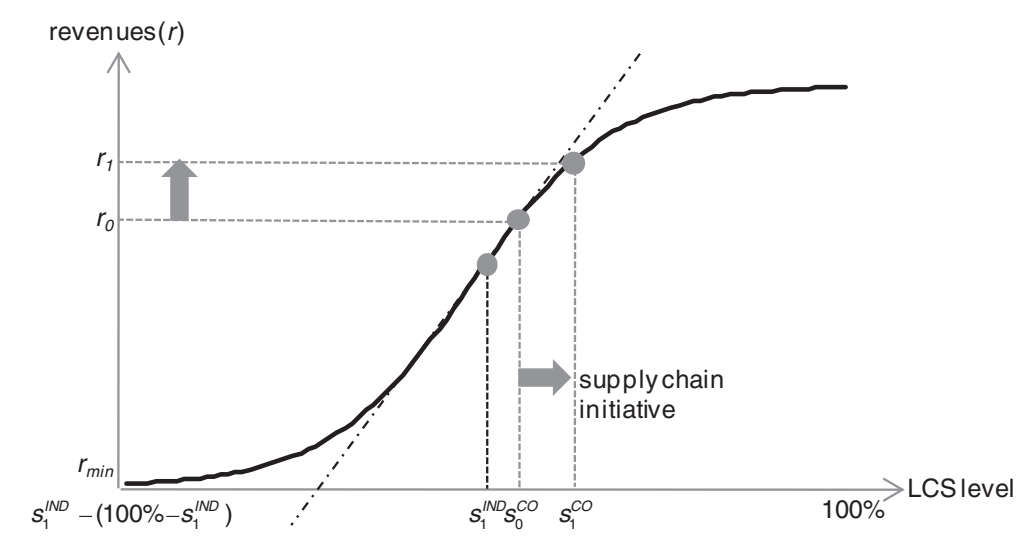

Figure 7 LCS-revenue curve in period $t=1$.

enhancement in period $t=1$. The revenue enhancement in future periods $(t=2)$ is covered by the second term. The effect for future periods is realized by dividing the term with the discounting factor $i$ which can be for example the weighted average cost of capital (WACC). Although the discounting can cover any amount of years, in this case, the future effects are considered for five periods to meet market dynamics and technological changes.

\section{Results and discussion}

\section{A case study from the consumer goods industry}

The introduced model was improved stepwise by conducting exploratory in-depth interviews. Subsequently, the results of one numerical example which was created with an international producer of consumer goods are presented. The in-depth interviews were arranged in November 2008 in Basel (Switzerland). The two interviewees came from the sales and logistics department. Actually, the interview consisted of three meetings. Firstly, the concept of the fuzzy model was presented and a potential SCI was identified. Secondly, the adapted questionnaire was completed (the questionnaire can be requested at the corresponding author). Thirdly, the results were evaluated and suggestions for improvement of the model were collected.

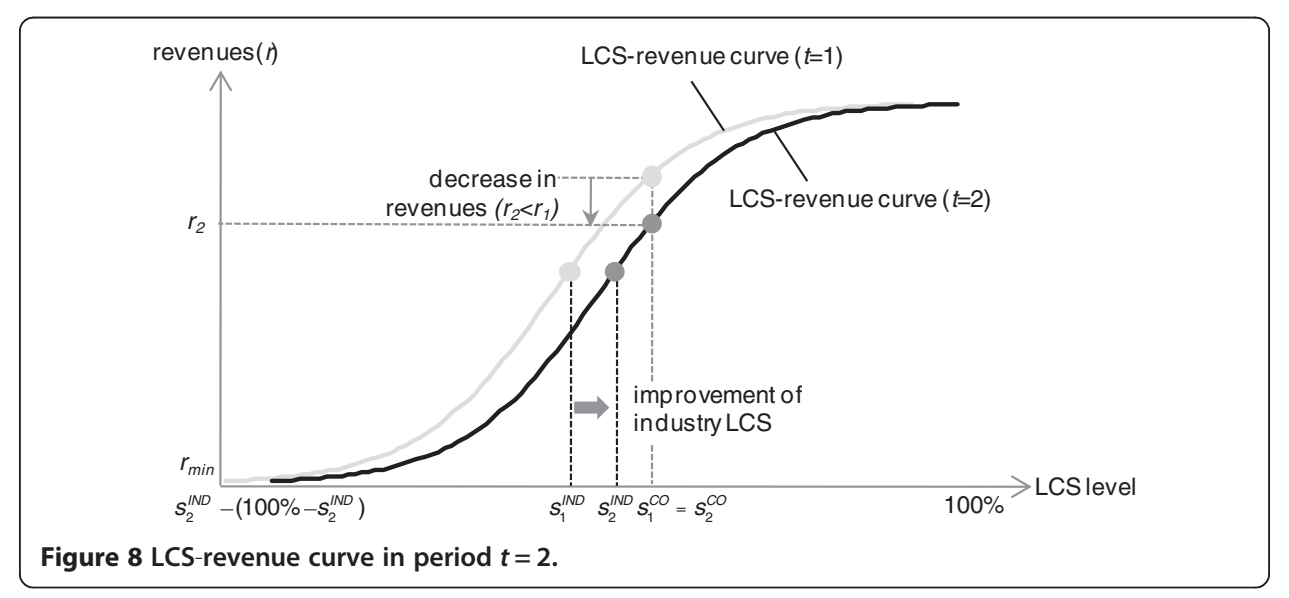


The focused company operates in the consumer goods industry. It offers a broad portfolio of products in the sectors laundry, cosmetics and adhesive technologies. The company sells its products in more than 100 countries worldwide and employs several ten thousand people. In 2008 they generated sales of $14 \mathrm{bn}$. Euro worldwide. The company faces a complex organizational structure due to a multilayer network of suppliers and customers in different countries and a broad portfolio of several hundred products. There are only a few production sites supplying the sales companies in the various countries. According to the expert knowledge of the interviewees, the focus of the following example is put on the cosmetics division in Switzerland with sales of approximately 65 Mio. CHF. The focused division already offers a high LCS. However, occasionally some unsteadiness in meeting customers demand in terms of temporally unavailability of products appears. Consequently, the company faces lost revenues and unsatisfied customers whose magnitude is unknown. The temporal unavailability of products is mainly led back to fluctuations in customers demand. This effect is amplified by the organizational structure designed of a few production sites supplying the national sales companies like that one in Switzerland. Generally, the production capacities are allocated to the sales companies in order of their demand forecasts. This method is inflexible to meet fluctuations in customers demand in specific countries. Since in most cases the products for the countries just differ in a country-specific label, a postponement of the labeling of the products can be realized as SCI. Postponement allows a delaying of the allocation of products to the different national sales companies and enhances flexibility without increasing safety stocks (Yang et al. 2007). The implementation of postponement improves LCS in enhancing the company's delivery flexibility and reliability.

\section{(I) Determination of case company's LCS $\left(\mathrm{s}^{\mathrm{CO}}\right.$ )}

The case company's LCS is determined by the weighting of the performance of the four factors lead time, delivery reliability, quality and flexibility according to their importance. The fuzzy comparison matrix reflects the judgment of the interviewees. The values of $\alpha$ and $\mu$ are both assumed to be 0.5. After applying Eq. (3) and (4), the fuzzy comparison matrix can be transferred to the second part shown in Eq. (8) from which eigenvalues and one eigenvector are derived.

$$
\tilde{A}=\left[\begin{array}{cccc}
1 & \tilde{1} & \tilde{3} & \tilde{3} \\
\tilde{1}^{-1} & 1 & \tilde{5} & \tilde{5} \\
\tilde{3}^{-1} & \tilde{5}^{-1} & 1 & \tilde{1} \\
\tilde{3}^{-1} & \tilde{5}^{-1} & \tilde{1}^{-1} & 1
\end{array}\right] \stackrel{\mu=\frac{1}{2} ; \alpha=\frac{1}{2}}{\longrightarrow} \tilde{A}=\left[\begin{array}{cccc}
1 & \frac{3}{2} & 3 & 3 \\
\frac{3}{4} & 1 & 5 & 5 \\
\frac{3}{8} & \frac{5}{24} & 1 & \frac{3}{2} \\
\frac{3}{8} & \frac{5}{24} & \frac{3}{4} & 1
\end{array}\right]
$$

By solving the characteristic equation $\operatorname{det}(\tilde{A}-\lambda \mathrm{I})=0$ the two real eigenvalues $\lambda_{1}=-0.1165$ and $\lambda_{2}=4.2644$ are obtained. Because the value of $\lambda_{2}$ is the largest, the corresponding eigenvector of matrix $\tilde{A}$ can derived by solving the equation $\tilde{A} \cdot \vec{x}=\lambda_{2} \cdot \vec{x}$. Normalization of the eigenvector determines the relative importance weights of lead time (38.9\%), delivery reliability (40.91\%), delivery quality (11.39\%) and delivery flexibility (9.6\%). The relative importance is used for the weighted average method proposed by 
(Chan et al. 2003). The corresponding data is shown in Table 4. The actual company's level of LCS is $96.53 \%$.

(II) Determination of the case industry's LCS $\left(\mathrm{s}^{\mathrm{IND}}\right)$

The calculation of $s^{I N D}$ is processed analogously to that of $s^{C O}$. The relative importance of the four service factors stays the same, simply the factor performance varies. Table 5 covers the corresponding data. In period $t=1$ the case industry LCS has a level of $95.24 \%$.

Beside the determination of $s^{I N D}$, the timely dynamics factor has to be considered to derive an adjustment between the periods $t=1$ and $t=2$. The intensity and the speed of competition are supposed to be $x_{0}=80$ and $y_{0}=65$. In application of the rule base shown in Table 2 and the rule of inference depicted in Eq. (5), the fuzzy output for the determination of the timely adjustment of $s^{I N D}$ is obtained. The aggregated output is shown in Figure 9. Using the MMM, an alteration of $0.75 \%$ between the periods $t=1$ and $t=2$ is calculated.

\section{(III) Determination of the elasticity of revenues ( $\eta$ )}

Firstly, the importance of LCS for customer's decision making has to be calculated in comparison to price, product and other factors (e.g. promotion). The relative importance is obtained by a fuzzy AHP analogously to Eq. (1) to (4). The input for the fuzzy comparison matrix and the output are shown in Table 6. The values of $\alpha$ and $\mu$ are 0.5 .

LCS has a relative importance of $11.39 \%$. Consequently, the input for the fuzzy approach is $v_{0}=0.114$. The other input is customer's expectations in LCS whose value is $w_{0}=80$. Considering the rule base depicted in Table 3 and the rule of inference shown in Eq. (5), the aggregated fuzzy output is of the nature pointed out in Figure 10. The elasticity of revenues is obtained by using the MMM. It has a value of 1.2.

\section{(IV) Modeling of the S-curve and derivation of revenue effects}

The S-curve is composed by $s^{I N D}$ which marks its inflection point and $\eta$ which displays its slope. The effect of the SCI "postponement" leads to an increase in $s^{C O}$ from $96.53 \%$ to 97.13\%. The enhancement is obtained by the weighted average method using the relative importance calculated for the four service factors. The initiative "postponement" has a

Table 4 Calculation of the case company's LCS

\begin{tabular}{|c|c|c|c|c|}
\hline & Lead time & Delivery reliability & Delivery quality & Delivery flexibility \\
\hline Relative importance & $38.9 \%$ & $40.91 \%$ & $11.39 \%$ & $9.6 \%$ \\
\hline Factor performance & 97 & 98 & 95 & 90 \\
\hline Perfect state & 100 & 100 & 100 & 100 \\
\hline Bottom state & 85 & 85 & 85 & 85 \\
\hline Performance score & 2.0 & 1.3 & 3.3 & 6.7 \\
\hline TFN $\tilde{A}$ & 0 & 0 & 0 & 0 \\
\hline TFN $\tilde{B}$ & 0 & 0 & 0 & 0.35 \\
\hline TFN $\tilde{C}$ & 0 & 0 & 0 & 0.65 \\
\hline TFN D & 0 & 0 & 0.65 & 0 \\
\hline TFN $\tilde{E}$ & 1 & 0.65 & 0.35 & 0 \\
\hline TFN $\tilde{F}$ & 0 & 0.35 & 0 & 0 \\
\hline Aggregated result (fuzzy output) & \multicolumn{4}{|c|}{$(0,0.0336,0.0624,0.074,0.6867,0.1432)$} \\
\hline Company LCS & \multicolumn{4}{|l|}{$96.53 \%$} \\
\hline
\end{tabular}


Table 5 Calculation of the case industry LCS

\begin{tabular}{|c|c|c|c|c|}
\hline & Lead time & Delivery reliability & Delivery quality & Delivery flexibility \\
\hline Relative importance & $38.9 \%$ & $40.91 \%$ & $11.39 \%$ & $9.6 \%$ \\
\hline Factor performance & 95 & 97 & 94 & 90 \\
\hline Perfect state & 100 & 100 & 100 & 100 \\
\hline Bottom state & 85 & 85 & 85 & 85 \\
\hline Performance score & 3.3 & 2.0 & 4.0 & 6.7 \\
\hline TFN $\tilde{A}$ & 0 & 0 & 0 & 0 \\
\hline TFN $\tilde{B}$ & 0 & 0 & 0 & 0.35 \\
\hline TFN $\tilde{C}$ & 0 & 0 & 0 & 0.65 \\
\hline TFN D & 0.65 & 0 & 1 & 0 \\
\hline TFN Ẽ & 0.35 & 1 & 0 & 0 \\
\hline TFN F & 0 & 0 & 0 & 0 \\
\hline Aggregated result (output) & \multicolumn{4}{|c|}{$(0,0.0336,0.0624,0.3616,0.5424,0)$} \\
\hline Company LCS & \multicolumn{4}{|l|}{$95.24 \%$} \\
\hline
\end{tabular}

strong impact on the delivery reliability (impact $=80)$ and flexibility (impact $=30$ ). By the time, $s^{I N D}$ rises up to $95.24 \%(+0.75 \%)$. The resulting curves are shown in Figures 11 and 12 .

The revenues of the company before the implementation of the SCI are $r_{0}=65.370$ mil. CHF. After the implementation, (period $t=1$ ) revenues of $r_{1}=65.779 \mathrm{mil}$. CHF are generated which means an enhancement of $0.063 \%$. By the time (period $t=2$ ) revenues decline to $r_{2}=65.718$ mil. CHF which is caused by the timely dynamics of $s^{I N D}$. The improvement of $s^{I N D}$ leads to a relative reduction of $s^{C O}$ associated with a relative reduction of the revenues in period $t=2$. Considering these effects for two periods, the implementation of postponement generates (excluding any costs) a net present value of 704' 000 CHF for the company (Eq. 9):

$$
N P V_{\text {postponement }}=\left(r_{0}-r_{1}\right)+\left(\frac{\left(r_{0}-r_{2}\right)}{(1+i)}\right)=0.409+\frac{0.348}{(1+0.05)}=0.704 \mathrm{mil} . \mathrm{CHF}
$$

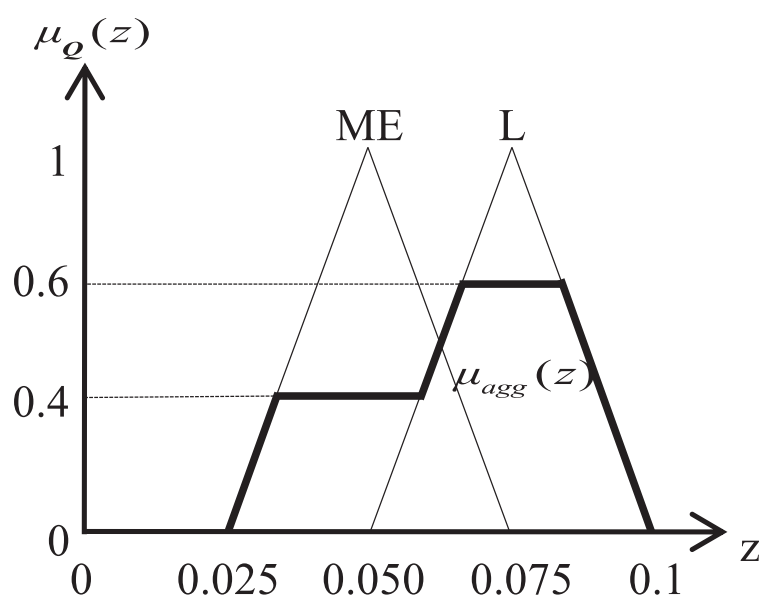

Figure 9 Aggregated output for the computation of the quality of competition. 
Table 6 Calculation of the relative importance of LCS

\begin{tabular}{lcccc}
\hline & Price & Product & LCS & Others (e.g. promotion) \\
\hline Price & 1 & $\tilde{3}$ & $\tilde{5}$ & 7 \\
Product & $\tilde{3}^{-1}$ & 1 & $\tilde{5}$ & 7 \\
LCS & $\tilde{5}^{-1}$ & $\tilde{5}^{-1}$ & 1 & $\tilde{5}$ \\
Others (e.g. promotion) & $\tilde{7}^{-1}$ & $\tilde{7}^{-1}$ & $\tilde{5}^{-1}$ & 1 \\
Relative importance $(\Sigma 100 \%)$ & $38.09 \%$ & $40.91 \%$ & $11.39 \%$ & $9.6 \%$ \\
\hline
\end{tabular}

\section{Critical reflection of case study and outlook}

The presented approach provides a monetary quantification of the relationship between the level of LCS and revenues. A company's decision makers have the opportunity to pre-estimate the financial effects of alterations in LCS. Given that, associated costs are comparably easy to determine, the approach supports management in investment decisions of SCIs by addressing the revenue side. In addition, the introduced model may cause a shift in focus of decision makers in terms of logistics and SCM, back from purely cost reduction to increasing revenues. The employment of multi criteria decision making might lead to reservations in terms of the validity of generated results. This is aggravated by the fact that the model was optimized and developed by a small number of companies. However, the discussions with project partners and run business cases curtail these concerns since the experts had trust in the strengths of fuzzy logic after short introductions into the technique and its mathematics. The high level of user friendliness ensured by an MS-Excel interface complies with the requirements of executives. Putting these considerations together, it can be stated that the introduced approach is a valuable support in decision-making in terms of investing in SCIs.

Altogether, our findings leave room for improvement that may be covered by future research:

- The fuzzy model has been adjusted on the basis of in-depth exploratory interviews. Consequently, the next step may be a large-scale testing to assure representativeness (Mangan et al. 2004). Beside a general improvement of validity, the results can be used for a differentiated consideration of LCS. At this stage, the presented model is

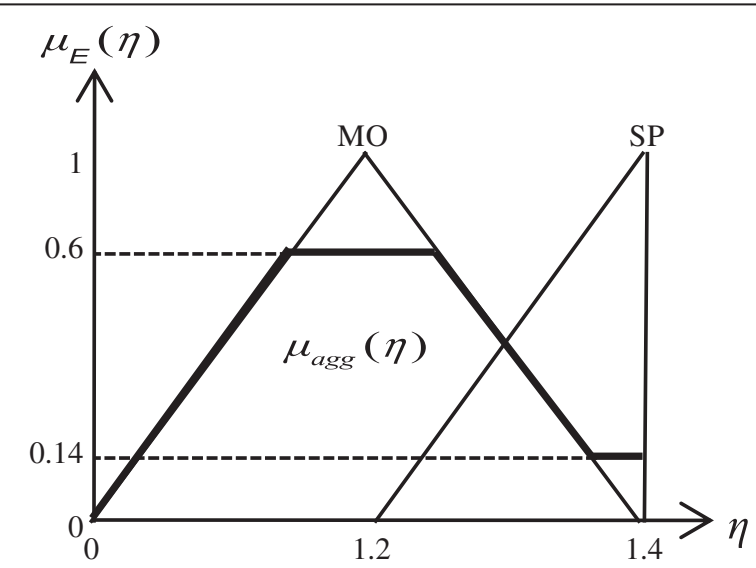

Figure 10 Aggregated output for the computation of the elasticity of revenues. 


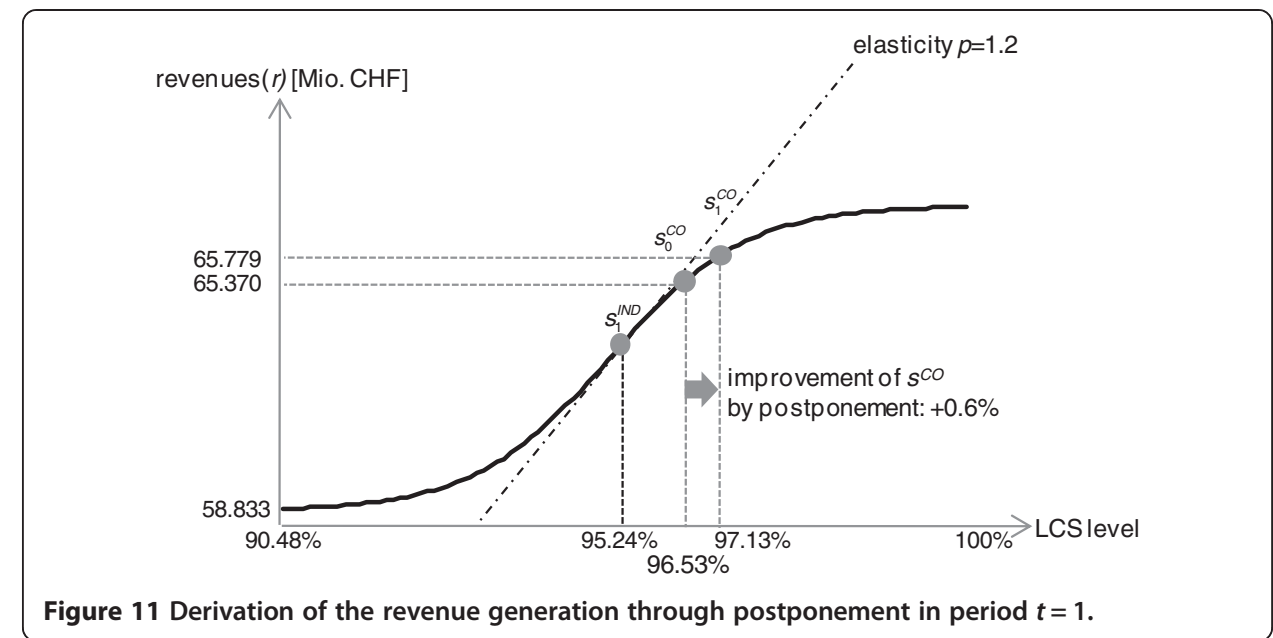

applicable for a defined product and customer base which may be a single or a group of items. In dependence of the homogeneity of the defined base, the results of the fuzzy model are conferrable. Especially a detailed consideration of different segments of customers improves the accuracy of the results because each customer segment is commonly provided with a specific level of LCS (Huiskonen and Pirttilä 1998).

- A further research field is the integration of a cost analysis for LCS offerings. With an improvement of the service level, specific investments, operating costs and working capital increase (Buxton 1975). In order to offer a profit maximizing LCS, it is crucial to know the revenue effect, as well as additional arising costs (Hofmann 2009; Lambert and Pohlen 2001; Pohlen and Coleman 2005). To implement a comprehensive calculation, differentiated functions for investments, operating costs and capital costs have to be formulated and opposed to the fuzzy model. For instance, the results of such an analysis can be transferred to the Economic Value Added, EVA (Hofmann and Locker 2009).

- According to the proposed model, the industry LCS would increase permanently until it reaches 100 percent, which is not possible. To counteract that development a disconfirmation of expectations has to be integrated which leads to a relative decrease of industry LCS (Oliver 1980, 2009).

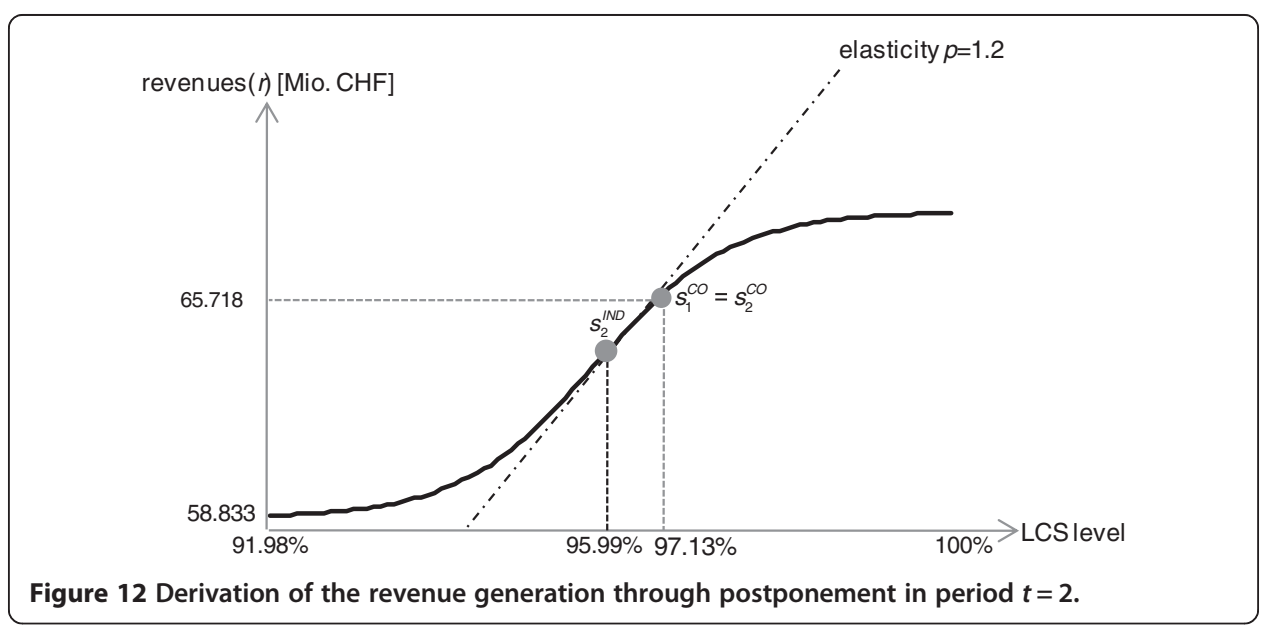


- Besides customer expectation, perception has to be considered (Gupta and Zeithaml 2006). Usually customers need time to notice improvements in a company's LCS which delays their reaction (Pisharodi and Langley 1990). Therefore, the complete revenue enhancement potential is not fully realized immediately after the implementation of a supply chain. This effect may be integrated in terms of a weighting factor for the revenue increase over time.

- While LCS has been assessed for a supplier-customer relationship, the financial effect of service improvements has not been explored in the context of the supply chain. Seth et al. (2006) highlight the necessity of exploring LCS quality in a more comprehensive setting, which means including all supply chain processes and operations that are associated with a specific product or service level.

- Besides LCS, also the market product, promotion activities and price were relevant factors which affect customer satisfaction and enhance revenues (Lambert and Stock 1993). These factors were not adequately considered within the introduced model. An increase in LCS level often goes along with an advance in price, which also effects customer satisfaction in an inverted way (Homburg et al. 2009). To get a comprehensive approach, the interactions between price advance and customer satisfaction may be integrated in the introduced model.

\section{Conclusion}

The paper at hand introduces an advanced fuzzy model for the pre-quantification of the effect of alterations in LCS level on company's revenues including dynamic reactions of competitors and customers. The alterations can be caused by any possible SCI. The crucial point of the quantification is the relation between LCS and revenues, becoming manifest in an S-shaped curve. The required components for the definition of the curve were computed by a fuzzy model. The enhanced AHP-model includes a standardization of LCS, by operationalizing it into the four service factors lead time, delivery quality, reliability and flexibility. This ensures comparability, due to different comprehensions of LCS in practice. Furthermore, the model considers external factors from a company's perspective in terms of industry characteristics, as well as customers' and competitors' reactions on alterations in LCS. An illustrative case from the Swiss consumer goods industry exemplifies the mechanics and outputs of the approach. Thus, the introduced model provides management support in decision-making in the context of a profitability assessment of SCIs targeting the level of LCS over time.

\section{Endnotes}

The introduced content has been published as part of Philip Wessely's dissertation "Value Determination of Supply Chain Initiatives: A Quantification Approach Based on Fuzzy Logic and System Dynamics" available at Gabler-Verlag, Wiesbaden 2011.

A former version of the paper "The Challenge of Business Logistics to Quantify the Financial Effects of Delivery Service Improvements" was presented at the 5th European Research Seminar ERS, Council of Supply Chain Management Professionals, Rotterdam, The Netherlands, March 24th 2010. 


\section{Authors' contributions}

PW carried out the fuzzy-logic model based on the profound literature review. He conducted the interviews in order to work out the case study. EH participated in the conceptual design and overall approach. He was responsible for the editorial finalization of the manuscript. Both authors read and approved the final manuscript.

\section{Authors' information}

Philip Wessely is a Senior Manager in an international consultancy company. His primary areas of interests are operations strategy, supply chain management and logistics optimization. He received his Doctor's degree from the University of St.Gallen (HSG), Switzerland, in Business Administration at the Chair of Logistics Management. The paper at hand is part of his cumulative dissertation with the title 'Value determination of supply chain initiatives'.

Erik Hofmann is Vice President of the Chair of Logistics Management as well as Assistant Professor at the University of St.Gallen, Switzerland. His primary research focuses on the intersections of operations management on one side and finance and performance as well as strategy issues on the other side. He has published in several academic journals (e.g.. Production Planning \& Control, Journal of Business Logistics and International Journal of Physical Distribution and Logistics Management). He is the (co-)author of more than ten books like Ways out of the Working Capital Trap or The Supply Chain Differentiation Guide.

\section{Acknowledgements}

This research was supported by the innovation promotion agency CTI of Switzerland (www.kti.admin.ch). The authors would like to thank the reviewers and editor for their constructive feedbacks and exceptionally comments.

\section{Author details}

A.T. Kearney (International) AG, Zurich, Switzerland. ${ }^{2}$ Logistics Management, University of St.Gallen, St.Gallen, Switzerland.

Received: 23 October 2013 Accepted: 25 October 2013

Published: 19 February 2014

\section{References}

Anderson, EW, Fornell, C, \& Lehmann, DR. (1994). Customer satisfaction, market share and profitability: Findings from Sweden. Journal of Marketing, 58(3), 53-66.

Arvis, J-F, Mustra, MA, Panzer, J, Ojala, L, \& Naula, T. (2007). Connecting to compete: Trade logistics in the global economy. The logistics performance index and its indicators. Washington: World Bank and International Bank for Reconstruction and Development.

Ballou, R. (2003). Business logistics / Supply chain management: Planning, organizing, and controlling the supply chain (5th ed.). Upper Saddle River: Prentice Hall.

Ballou, R. (2006). Revenue estimation for logistics customer service offerings. International Journal of Logistics Management, 17(1), 21-37.

Bolton, RN. (1998). A dynamic model of the duration of the customer's relationship with a continuous service provider: The role of satisfaction. Marketing Science, 17(1), 45-65.

Bookbinder, JH, \& Lynch, ME. (1997). Customer service in physical distribution: A utility-function approach. International Journal of Physical Distribution \& Logistics Management, 27(9/10), 540-559.

Boulding, W, Kalra, A, Staelin, R, \& Zeithaml, VA. (1993). A dynamic process model of service quality: From expectations to behavioral intentions. Journal of Marketing Research, 30(1), 7-27.

Buxton, G. (1975). Effective Marketing Logistics. Macmillan, London: The Analysis, Planning and Control of Distribution Operations.

Chan, FTS, \& Qi, HJ. (2003). An innovative performance measurement method for supply chain management. Supply Chain Management: An international Journal, 8(3), 209-223.

Chan, FTS, Qi, HJ, Chan, HK, Lau, HCW, \& Ip, RWL. (2003). A conceptual model of performance measurement for supply chains. Management Decision, 41(7), 635-642.

Chow, CC, \& Luk, P. (2005). A strategic service quality approach using analytic hierarchy process. Managing Service Quality, 15(3), 278-289.

Cronin, JJ, \& Taylor, S. (1994). SERVPERF versus SERVQUAL: reconciling performance-based and perception -minus-expectations measurement of service quality. Journal of Marketing, 58(1), 125-131.

Danaher, PJ, \& Rust, RT. (1996). Indirect financial benefits from service quality. Quality Management Journal, 3(2), 63-75.

Deng, WJ. (2008). Fuzzy importance-performance analysis for determining critical service attributes. International Journal of Service Industry Management, 19(2), 252-270.

Dresner, M, \& Xu, K. (1995). Customer service, customer satisfaction, and corporate performance in the service sector. Journal of Business Logistics, 16(1), 23-40.

Ellram, LM, \& Liu, B. (2002). The financial impact of supply management. Supply Chain Management Review, $6(6), 30-37$.

Fornell, C. (1992). A national customer satisfaction barometer. The Swedish experience. Journal of Marketing, $56(1), 6-21$

Fornell, C, Mithas, S, Morgeson, FV, III, \& Krishnan, MS. (2006). Customer satisfaction and stock prices: High returns, low risk. Journal of Marketing, $70(1), 3-14$

Gupta, S, \& Zeithaml, VA. (2006). Customer metrics and their impact on financial performance. Marketing Science, 25(6), 718-739.

Handfield, R, Warsing, D, \& Wu, X. (2009). Inventory policies in a fuzzy uncertain supply chain environment. European Journal of Operational Research, 197(2), 609-619.

Hofmann, E. (2009). Inventory financing in supply chains - A logistics service provider-approach. International Journal of Physical Distribution \& Logistics Management, 39(9), 716-740 
Hofmann, E, \& Locker, A. (2009). Value-based performance measurement in supply chains: a case study from the packaging industry. Production Planning \& Control, 20(1), 68-81.

Homburg, C, \& Giering, A. (2001). Personal characteristics as moderators of the relationship between customer satisfaction and loyalty - an empirical analysis. Psychology \& Marketing, 18(1), 43-66.

Homburg, C, Hoyer, WD, \& Koschate, N. (2009). Customer's reaction to price increase: Do customer satisfaction and perceived motive fairness matter? Journal of the Academy of Marketing Science, 33(1), 36-49.

Hsin-Hui, HUA, Kandampully, H, \& Juwaheer, JTD. (2009). Relationships and impacts of service quality, perceived satisfaction, and image: An empirical study. The Service Industries Journal, 29(2), 111-125.

Huiskonen, J, \& Pirttilä, T. (1998). Sharpening logistics customer service strategy planning by applying Kano's quality element classification. International Journal of Production Economics, 56-57(3), 253-260.

IBM Institute for Business Value. (2008). The GMA 2008 Logistics Survey, Improving efficiency in the face of mounting logistics costs. Somers, NY: IBM Corporation.

Innis, D, \& La Londe, B. (1994). Customer service: The key to customer satisfaction, customer loyalty, and market share. Journal of Business Logistics, 15(1), 1-27.

Kamakura, W, Mittal, V, de Rosa, F, \& Afonso, J. (2002). Assessing the service-profit chain. Marketing Science, 21(3), 294-317.

Kasanen, E, Lukka, K, \& Siitonen, A. (1993). The constructive approach in management accounting research. Journal of Management Accounting Research, 5(1), 243-264.

Klir, GJ, \& Yuan, B. (1995). Fuzzy sets and fuzzy logic: Theory \& application. Upper Saddle River: Prentice-Hall.

Kwong, CK, \& Bai, H. (2002). A fuzzy AHP approach to the determination of importance weights of customer requirements in quality function deployment. Journal of Intelligent Manufacturing, 13(5), 367-377.

Lambert, DM, \& Burduroglu, R. (2000). Measuring and selling the value of logistics. International Journal of Logistics Management, 11(1), 1-17.

Lambert, DM, \& Pohlen, T. (2001). Supply chain metrics. The International Journal of Logistics Management $12(1), 1-19$

Lambert, DM, \& Stock, JR. (1993). Strategic Logistics Management (3rd ed.). Boston: Homewood.

Lee, AR. (1995). Application of modified Fuzzy AHP method to analyze bolting sequence of structural joints (PhD Dissertation). Lehigh University, A Bell \& Howell Company. UMI Dissertation Services.

Luo, X, \& Homburg, C. (2008). Satisfaction, complaint, and the stock value gap. Journal of Marketing, 72(4), 29-43.

Mangan, J, Lalwani, C, \& Gardner, B. (2004). Combining quantitative and qualitative methodologies in logistics research. International Journal of Physical Distribution \& Logistics Management, 34(7), 565-578.

Mentzer, JT, Flint, DJ, \& Kent, JL. (1999). Developing a logistics customer service quality scale. Journal of Business Logistics, 1(1), 9-32.

Meredith, J. (1993). Theory building through conceptual methods. International Journal of Operations \& Production Management, 13(5), 3-11.

Mittal, V, \& Kamakura, W. (2001). Satisfaction, repurchase intent, and repurchase behavior: Investigating the moderating effect of customer characteristics. Journal of Marketing Research, 38(1), 131-142.

Oliver, RL. (1980). A cognitive model of the antecedents and consequences of satisfaction decisions. Journal of Marketing Research, 17(4), 460-469.

Oliver, RL. (2009). Evaluating the expectations disconfirmation and expectations anchoring approaches to citizen satisfaction with local public services. Journal of Public Administration Research \& Theory, 19(1), 107-123.

Ozment, J, \& Chard, N. (1986). Effects of customer service on sales: An analysis of historical data. Inter. Journal of Physical Distribution \& Logistics Management, 16(3), 14-28.

Parasuraman, A, Zeithaml, VA, \& Berry, LL. (1985). A conceptual model of service quality and its implications for future research. Journal of Marketing, 49(4), 41-50.

Parasuraman, A, Zeithaml, VA, \& Berry, LL. (1988). SERVQUAL: a multiple-item scale for measuring consumer perceptions of service quality. Journal of Retailing, 64(1), 12-40.

Parasuraman, A, Berry, LL, \& Zeithaml, VA. (1991). Refinement and Reassessment of the SERVQUAL scale. Journal of Retailing, 67(4), 420-451.

Pisharodi, RM, \& Langley, CJ, Jr. (1990). A perceptual process model of customer service based on cybernetic/control theory. Journal of Business Logistics, 11(1), 26-48.

Pohlen, TL, \& Coleman, BJ. (2005). Evaluating internal operations and supply chain performance using EVA and ABC SAM Advanced Management Journal, 70(2), 45-58.

Saaty, T. (2003). Decision-making with the AHP: Why is the principal eigenvector necessary? European Journal of Operational Research, 145(1), 85-92.

Seth, N, Deshmukh, G, \& Vrat, P. (2006). A framework for measurement of quality of service in supply chains. Supply Chain Management: An International Journal, 11(1), 82-94

Sterling, JU, \& Lambert, DM. (1989). Customer service research: past, present, and future. International Journal of Physical Distribution \& Materials Management, 19(2), 14-17.

Takeuchi, H, \& Quelch, J. (1983). Quality is more than making a good product. Harvard Business Review, 61(4), 139-145.

Theeranuphattana, A, \& Tang, J. (2008). A conceptual model of performance measurement for supply chains. Journal of Manufacturing Technology Management, 19(1), 125-148.

Tracey, M. (1998). The importance of logistics efficiency to customer service and firm performance. The International Journal of Logistics Management, 9(2), 65-81.

Vickery, SK, Jayaram, J, Droge, C, \& Calantone, R. (2003). The effect of an integrative supply chain strategy on customer service and financial performance: An analysis of direct versus indirect relationships. Journal of Business Logistics, 21(5), 523-539.

Wouters, M. (2006). Economic evaluation of supply chain management initiatives. Supply Chain Management: An International Journal, 11(6), 510-521.

Yang, B, Yang, Y, \& Wijngaard, J. (2007). Postponement: An inter-organizational perspective. International Journal of Production Research, 45(4), 971-988. 
Yeung, AC. (2008). Strategic supply management, quality initiatives, and organizational performance. Journal of Operations Management, 26(4), 490-502.

Zeithaml, VA, Berry, LL, \& Parasuraman, A. (1988). Communication and control process in delivery of service quality. Journal of Marketing, 52(2), 35-48.

Zeithaml, VA, Berry, LL, \& Parasuraman, A. (1996). The behavioral consequences of service quality. Journal of Marketing, $60(2), 31-46$.

doi:10.1186/2193-8636-1-2

Cite this article as: Wessely and Hofmann: Determining the revenue contribution of logistics customer service improvements: a multi criteria decision making approach. Decision Analytics 2014 1:2.

Submit your manuscript to a SpringerOpen ${ }^{\circ}$ journal and benefit from:

- Convenient online submission

- Rigorous peer review

- Immediate publication on acceptance

- Open access: articles freely available online

- High visibility within the field

- Retaining the copyright to your article

Submit your next manuscript at $>$ springeropen.com 